[Bull. Agr. Chem. Soc. Japan, Vol. 21, No. 1, p. 1 4, 1957]

\title{
Studies on the Metabolic Products of Macrosporium porri Elliott
}

\author{
Part I. Isolation and General Properties of Macrsporin, A New Pigment
}

\author{
By Rikisaku Suemitsu, Yukio Matsur, and Makoto Hiura \\ Instilute of Dairy Chemistry, Rakuno College \\ Received February 11, 1956
}

\begin{abstract}
A strain of Macrosporium porri Elliott, when grown at $25^{\circ}$ on $2 \%$ glucose solution of stoneleek decoction, gives rise to a hitherto undescribed pigment to which the name "macrosporin" is proposed. Optimum cultural condition for the production of the pigment and the method of its isolation are described here. Macrosporin, $\mathrm{C}_{16} \mathrm{H}_{12} \mathrm{O}_{5}$, crystallizes as orange-yellow rhombic and melts at $300-302^{\circ}$ with decomposition. General properties of macrosporin, its diacetate, m.p. 209-210 ${ }^{\circ}$, and trimethylether, m.p. 260-261 , are described. Macrosporin is recognized to be a hydroxyanthraquinone derivative from the results of elementary analysis, molecular weight determination, and ultra-violet and infra-red spectra.
\end{abstract}

In the previous literature, there are many reports concerning the pigments produced by species of Penicillium, Helminthosporium, Aspergillus, and Fusarium. However, nothing has been reported, either on the pigments, or on the metabolic products of Macrosporium. Two crystalline pigments were isolated from the mycelia of Macrosporium porri Elliott, which is known as a pathogenic organism causing the black spot disease of stone-leek, cultured in liquid media for 25 days. For one of them, hitherto undescrived, the name "macrosporin" is proposed in connection of the species name, while the other pigment will be described later. Macrosporin, $\mathrm{C}_{16} \mathrm{H}_{12} \mathrm{O}_{5}$, m.p. 300-302 (decom.) is an orange-yellow pigment having anthraquinone-like properties. It is easily soluble in $\mathrm{N}-\mathrm{NaOH}$ and $\mathrm{N}-\mathrm{Na}_{2} \mathrm{CO}_{3}$ to give purple-red solution and, on acidifying with $\mathrm{HCl}$ the pigment is regenerated.

It dissolves in conc. $\mathrm{H}_{2} \mathrm{SO}_{4}$ to give an orange-red solution. It dissolves very sparingly in almost all of the organic solvents. Its glacial acetic acid solution is yellow in color, and does not show fluorescence in daylight. The color disappears on reducing with zinc dust and the color is restored by standing for a while. This color-reaction is characteristic of the $p$-quinone type compounds. Its alcoholic solution gives darkbrown color with ethanolic $\mathrm{FeCl}_{3}$ and orangeyellow color with ethanolic magnesium acetate $^{1)}$.

The ultra-violet absorption spectrum shows absorption bands, $2 \max .225 \mathrm{~m} \mu(\log .4 .32)$ indicating dihydroxyanthraquinone ${ }^{2)}$ structure, and $\lambda \max .285 \mathrm{~m} \mu(\log .4 .30)^{3)}$ also indicating the characteristic of quinoid nucleus of anthraquinone besides a broad band $\lambda \max$. $381 \mathrm{~m} \mu$ (log. 3.90).

The infra-red spectrum of macrosporin gives a non-chelated carbonyl band at $6.02 \mu$, chelated carbonyl band at $6.11 \mu$, and a band by the hydroxyl group located the $\beta$-position to carbonyl group at $\left.3.04 \mu^{4}\right)$. As it is apparent that in every case, when a hydroxyl group not adjacent to a carbonyl group is present, a band is to be obserbed at about $2.99 \mu$, and macrosporin is believed to contain a hydroxyl

1) S. Shibata, et al., J. Am. Cbem. Soc, 72, 2789 (1950).

2) T. Ikeda, et al., J. Pbarm. Sor. Japan, 76, 217 (1956).

3) L.H. Briggs, et al., J. Chem. Sor., 1952, 1718.

4) M. St, C. Flett J. Cbem. Soc., 1948, 1441. 


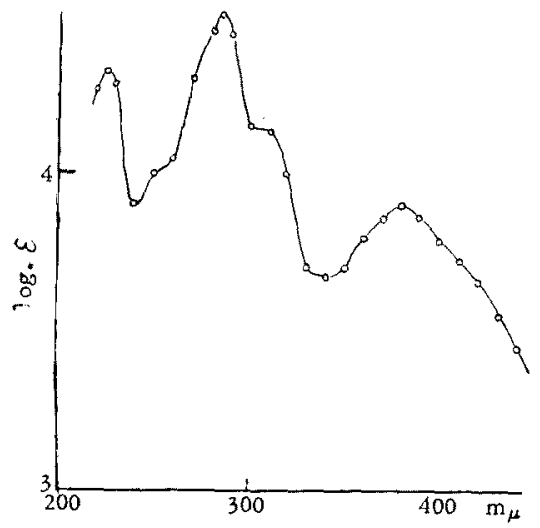

FIG. 1. UV-absorption Spectrum of Macrosporin. $\left(5 \times 10^{-5} \mathrm{~mol}\right.$ ethanol solution)
Judging from its general properties and both ultra-violet and infra-red absorption data of macrosporin, it is very probable that macrosporin may be a hydroxyanthraquinone derivative represented by formula, $\mathrm{C}_{16} \mathrm{H}_{12} \mathrm{O}_{5}$, involving 1 methoxy group and 2 hydroxyl groups, one of which may be located at least in the $\beta$-position to the carbonyl group.

Six of the pigments produced by microorganisms have been previously reported to involve the methoxy group. They are: roseopurpurin (4-methoxy-emodin), phycion (7-methoxy-emodin), erythroglaucin (7methoxy-catenarin), nalgiovensin (4,5-dihydroxy-7-methoxy-2-hydroxypropylanthraqui-

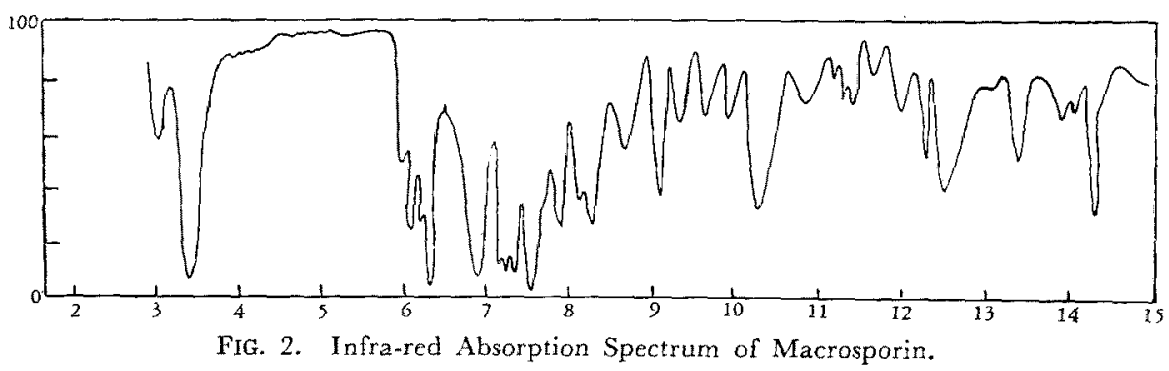

group $\beta$-positioned to carbonyl group in it.

On treatment with acetic anhydride in the presence of a trace amount of conc. $\mathrm{H}_{2} \mathrm{SO}_{4}$, macrosporin gives diacetate, $\mathrm{C}_{16} \mathrm{H}_{10} \mathrm{O}_{5}$ $\left(\mathrm{COCH}_{3}\right)_{2}$, light yellow needles, m.p. 209-210 and on boiling with dimethyl sulfate and $\mathrm{K}_{2} \mathrm{CO}_{3}$ in acetone, it gives a trimethylether $\mathrm{C}_{15} \mathrm{H}_{7} \mathrm{O}_{2}\left(\mathrm{OCH}_{3}\right)_{3}$, yellow needles, m.p. 260$261^{\circ}$. On determination of the methoxy group by Zeisel's method both macrosporin and diacetate give 1 methoxy group respectively, while trimethylether gives 3 methoxy groups.

Some reports concerning the paper chromatography of hydroxyanthraquinone ${ }^{1,5}$ ) have been given by Shibata et al. By using Shibata's solvent system it was found that an orange spot of $R_{F} 0.37$ is given only with butanol saturated with $28 \% \mathrm{NH}_{4} \mathrm{OH}$.

\footnotetext{
5) M. Takido, Pharm. Bull., 4, 45 (1956).
}

none), nalgiolaxin (1 or 8-chloronalgiovensin), and carviolin (4-methoxy-w-hydroxyemodin). Though a few hydroxyanthraqninone6,7,8) derivatives having the methoxy group have been obtained from other sources they are not identical with macrosporin.

\section{EXPERIMENTAL}

Culture. The strain of Macrosporium porri Elliott used in this work, was obtained from the experimental field attached to our college.

Cultural Condition. Two $\%$ glucose solution of stone-leek decoction was used as the cultural medium. A number of $500-\mathrm{ml}$ Erlenmyer flasks, containing 150 $\mathrm{ml}$ of the solution, $\mathrm{pH} 6.5-7.0$, were sterillized and inoculated with the strain which had been freshly cultured. The inoculated flasks were incubated at $25^{\circ}$ in the dark. On the 5 th day the mycelia were light-cream in color and covered the surface of the

6) R. Hill, Nature, 134, 628 (1934).

7) A.G. Perkin, J. Chem. Soc., 91, 2066 (1907).

8) S. Nonomura, J. Pbarm. Soc. Japan, 75, 219 (1955). 


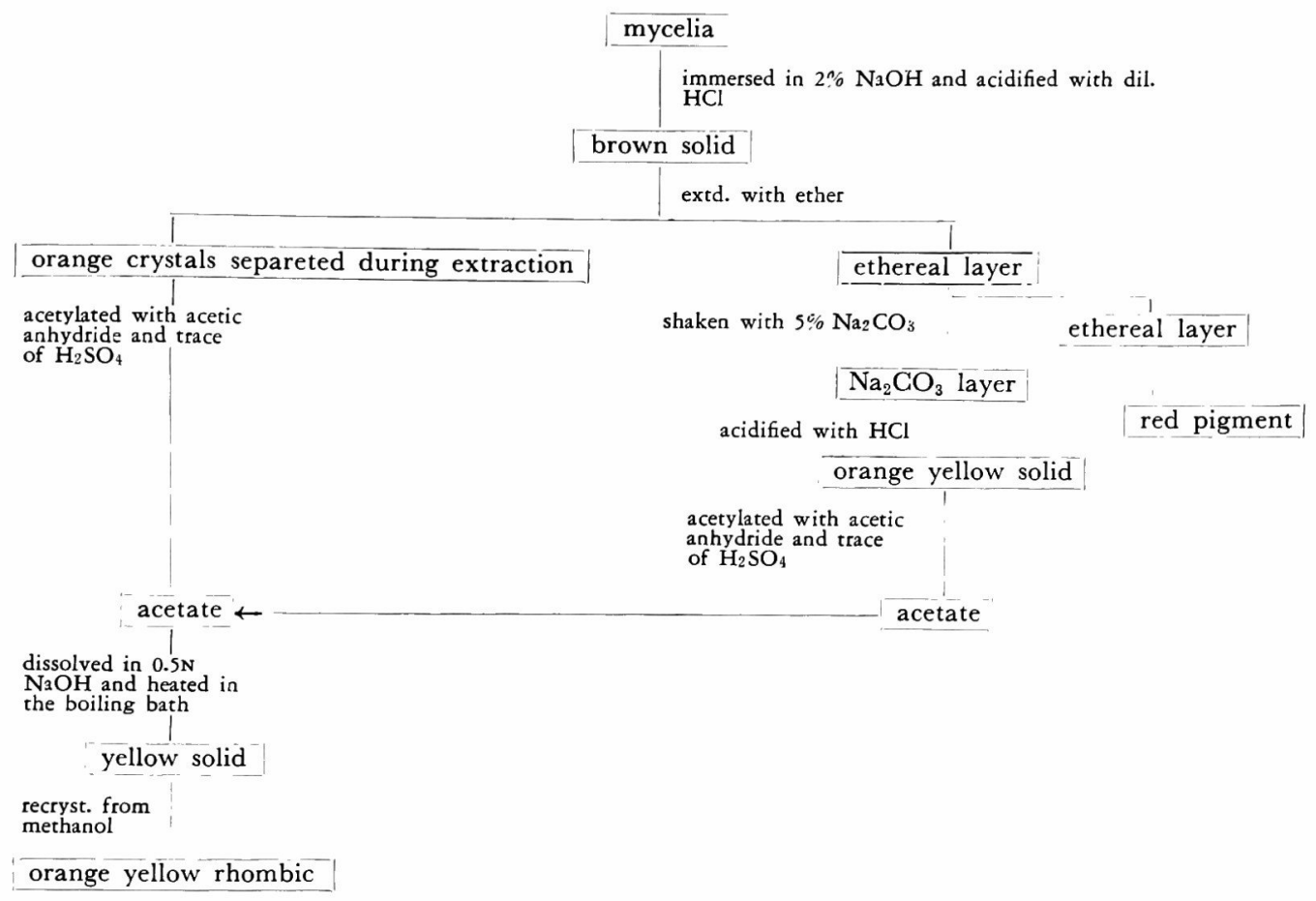

FIG. 3. Isolation and Purification of the Pigment.

medium, and became yellow-orange on the 10th day. When harvested, at the end of 25 days, the mycelia became dark-red in color and the solution also turned dark-red.

Isolation and Purification of the Pigment. The mycelia were filtered by cloth, dried at $45^{\circ}$ and powdered. The method of purification of the pigment is given in Fig. 3.

As it was doubtful that the pigment obtained by the method described in Fig. 3 might undergo change by $\mathrm{NaOH}$ treatment, the dried mycelia were directly extracted with ether and in this way the yellow-orange pigment was obtained. The pigment was identical with the one which was mentioned before. About $0.6 \mathrm{~g}$ of crystalline pigment was obtained from $10.4 \mathrm{l}$ of substrate and its weight was about $2.5 \%$ of the dried mycelium.

General Properties of Macrosporin. Macrosporin crystallizes from glacial acetic acid as beautiful orangeyellow rhombic, m.p. 300-302 ${ }^{\circ}$ (decomp.) Anal. Found: C, $67.40 ; \mathrm{H}, 4.39 ; \mathrm{OCH}_{3}, 10.17$; Cald. for $\mathrm{C}_{15} \mathrm{H}_{9} \mathrm{O}_{4}{ }^{-}$ $\mathrm{OCH}_{3}$ : C, 67.60; H, 4.26; $\mathrm{OCH}_{3}, 10.91$.

It readily sublimes at about $280^{\circ}$, does not dissolve

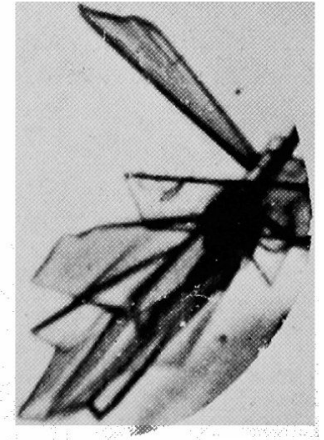

FIG. 4. Crystals of Macrosporin. ( $\times$ 640) 
in sat. $\mathrm{NaHCO}_{3}$, but dissolves in $\mathrm{N}-\mathrm{Na}_{2} \mathrm{CO}_{3}$ to a purple-red solution and readily dissolves in $\mathrm{N}-\mathrm{NaOH}$ to a deep purple-red solution. Its ethanolic solution gives a darkbrown color with ethanolic $\mathrm{FeCl}_{3}$ and orange-yellow color with ethanolic magnesium acetate. It dissolves in conc. $\mathrm{H}_{2} \mathrm{SO}_{4}$ to an orange-red solution. Its glacial acetic acid solution is yellow in color, and does not give rise to fluoresence in daylight. Macrosporin hardly dissolves in ether, benzene, cbloroform and toluene, but dissolves in hot acetone, hot ethanol and hot glacial acetic acid.

Macrosporin Diacetate. Macrosporin $(0.1 \mathrm{~g})$ was dissolved in acetic anhydride $(10 \mathrm{ml})$ and a drop of conc. $\mathrm{H}_{2} \mathrm{SO}_{4}$ was added. It was then cooled and poured into water. The dark-yellow solid separated was filtered, dried and crystallized from methanol to give fine light needles $(0.07 \mathrm{~g})$, m.p. 209-210 . Anal. Found: C, 65.26; H, 4.52; $\mathrm{OCH}_{3}, 8.23$; M.W. (Rast) 371 ; Cald. for $\mathrm{C}_{15} \mathrm{H}_{7} \mathrm{O}_{5}\left(\mathrm{COCH}_{3}\right)_{2} \mathrm{OCH}_{3}$ : C, $65.21 ; \mathrm{H}, 4.38 ; \mathrm{OCH}_{3} 8.42 ;$ M.W. 368 .

Macrosporin Trimethylether. A mixture of macrosporin $(0.55 \mathrm{~g})$, anhydrous $\mathrm{K}_{2} \mathrm{CO}_{3}(30 \mathrm{~g})$, redis- tilled dimethyl sulfate $(4 \mathrm{ml})$ and dry acetone $(200 \mathrm{ml})$ was boiled under reflux. After boiling for $3 \mathrm{hrs}$, anhydrous $\mathrm{K}_{2} \mathrm{CO}_{3}(15 \mathrm{~g})$ and dimethyl sulfate $(4 \mathrm{ml})$ were added and the reaction was continued further for a period of 7 hours. The hot solution was filtered and evaporated to a yellow solid, which was recrystallized from acetone and finally from methanol to give yellow needles $(0.4 \mathrm{~g})$, m.p. $260-261^{\circ}$. Anal. Found: C, $69.09 ; \mathrm{H}, 5.17 ; \mathrm{OCH}_{3}, 28.30$; Cald. for $\mathrm{C}_{15} \mathrm{H}_{7} \mathrm{O}_{2}-$ $\left(\mathrm{OCH}_{3}\right)_{3}: \mathrm{C}, 69.22 ; \mathrm{H}, 5.16 ; \mathrm{OCH}_{3}, 29.81$.

Paper Chromatography of Macrosporin. Ethanol solution of the pigment was placed on a filter paper (Toyo Roshi No. 3, $1.5 \times 25$ ) and developed at $18^{\circ}$ by one-dimentional decending method using butanol saturated with $28 ; 6 \mathrm{NH}_{4} \mathrm{OH}$ as the developing solvent. The developed paper was dried and the spot was examined. color; orange, $R_{k^{r}} ; 0.37$.

We are indebted to Prof. Igarashi of Hokkaido Univ., Prof. Takei of Kyoto Univ., for their good suggestions and Prof. Mitsui of Kyoto Univ. for the elementary analysis. 